\title{
POSTURA FISCAL Y CRECIMIENTO ECONÓMICO REGIONAL EN COLOMBIA*
}

\author{
HENRY ANTONIO MENDOZA TOLOSA" \& JACOBO CAMPO ROBLEDO"** \\ UNIVERSIDAD CATÓLICA DE COLOMBIA
}

Recibido/ Received/Recebido: 21/11/2014 - Aceptado/ Accepted / Aprovado: 24/11/2015

\begin{abstract}
Resumen
Este documento estudia la forma en que ha incidido el gasto público en la actividad económica de los departamentos en Colombia durante el periodo 2000-2013, a partir de la aplicación de diferentes técnicas derivadas de medición económica cuyos resultados se confrontan para explicar la intencionalidad de la postura fiscal de los gobiernos territoriales en sus economías. En este sentido, se desea representar cómo ha influido el gasto público en el producto regional y en qué magnitud los departamentos han aportado al PIB nacional, identificando los rasgos fiscales distintivos de dicho impacto, con el fin de explicar en qué sentido dicha asignación es eficiente para las regiones. Entre las diferentes herramientas empleadas se combinan técnicas de $\mathrm{MCO}$, con aportes relativos al crecimiento, índices de localización y/o especialización del gasto público, de la formación bruta de capital fijo y del valor agregado, evaluados con su desempeño fiscal particular durante toda la serie. Los resultados muestran que las regiones que han aprovechado mejor la asignación de recursos públicos en Colombia, sin importar el nivel del gasto, han obtenido mejor desempeño de sus economías, contrario a las tesis que plantean que el gasto público por sí sólo es un dinamizador de la actividad.
\end{abstract}

Palabras clave: Desempeño fiscal; Postura fiscal; PIB; Crecimiento económico regional.

\section{FISCAL STANCE AND REGIONAL ECONOMIC GROWTH IN COLOMBIA}

\begin{abstract}
This paper studies how public spending has affected the economic activity of the departments in Colombia during the period 2000-2013, from the application of different techniques derived from economic measurement whose results are compared to explain the intent of the fiscal stance of territorial governments in their economies. In this sense, we want to represent how it has influenced public spending on the regional product; and to what extent departments have contributed to national GDP identifying such impact's distinctive tax traits in order to explain the reason this allocation is efficient for regions. Among the different tools used MCO techniques are combined with contributions related to growth, rates of localization and / or specialization of public expenditure, the fixed capital's gross formation and added value. They are evaluated with its particular fiscal performance throughout the series. The results show that the regions that have better utilized the allocation of public resources in Colombia, regardless of the level of spending, they have obtained
\end{abstract}

\footnotetext{
Artículo de investigación, derivado del proyecto titulado: "Impacto del Gasto Público en la Dinámica Económica Regional a través del Sistema de Cuentas Nacionales Departamentales" vinculado a la Universidad Católica de Colombia.

* Investigador, Grupo Finanzas y Política Económica, Facultad de Ciencias Económicas y Administrativas de la Universidad Católica de Colombia. Dirección postal: Carrera 13 No. 47-49, Facultad de Ciencias Económicas y Administrativas, Universidad Católica de Colombia, Bogotá. Teléfono: 00+57(1) 3277300 Ext. 1555. Correo electrónico: hamendoza@ucatolica.edu.co

*** Investigador, Grupo Finanzas y Política Económica, Facultad de Ciencias Económicas y Administrativas de la Universidad Católica de Colombia. Correo electrónico: jacampo@ucatolica.edu.co.
} 
better performance of their economies, contrary to the arguments posed that public spending alone is an active catalyst.

Keywords: Fiscal performance; Fiscal stance; GDP; Regional economic growth.

\title{
POSTURA FISCAL E CRESCIMENTO ECONÔMICO REGIONAL NA COLÔMBIA
}

\begin{abstract}
Resumo
Este documento estuda a forma como o gasto público incidiu na atividade econômica dos departamentos da Colômbia durante o período entre 2000 e 2013. Tal estudo se realiza a partir da aplicação de diferentes técnicas derivadas da medição econômica, cujos resultados se confrontaram, com o fim de explicar a intencionalidade da postura fiscal dos governos territoriais em suas economias. Neste sentido, deseja-se apresentar como o gasto público influenciou o produto regional e em que magnitude os departamentos contribuíram com o PIB nacional, identificando as características fiscais específicas deste impacto, com o fim de explicar em que sentido esta contribuição é eficiente para as regiões. Entre as diferentes ferramentas utilizadas combinam-se técnicas de $\mathrm{MCO}$, com dados relacionados ao crescimento, índices de localização e/ou especialização do gasto público, da formação bruta de capital fixo e do valor agregado, avaliados a partir de seu desempenho fiscal particular durante toda a série. Os resultados mostram que as regiões que melhor aproveitaram da contribuição de recursos públicos na Colômbia, sem importar o nível da despesa, têm obtido melhor desempenho de suas economias, contrário às teses segundo as quais o gasto público por si só é um dinamizador da atividade.
\end{abstract}

Palavras chave: Desempenho fiscal; Postura fiscal; PIB; Crescimento econômico regional.

Mendoza, H. \& Campo, J. (2016). Postura fiscal y crecimiento económico regional en Colombia. En: Revista de la Facultad de Ciencias Económica: Investigación y Reflexión. rev.fac.cienc.econ, XXIV (2), DOI: http://dx.doi.org/10.18359/rfce.2211

JEL: H72, R10, R50.

\section{Introducción}

Los estudios para determinar la relación entre el gasto público y el crecimiento económico se han enfocado predominantemente al análisis de convergencia antes que a la determinación de instrumentos para explicar su grado de impacto en el PIB. No obstante, mención particular a trabajos como el de Galvis \& Roca (2000) que revisando la dinámica económica de algunas ciudades mediante el uso de métodos cuantitativos, encontraron que la magnitud del capital humano y la infraestructura de las urbes constituían para entonces factores de crecimiento del PIB per cápita, siempre y cuando se ejecutaran en niveles óptimos para constituirse en impulsores de crecimiento. Posteriormente, Gómez \& Posada
(2003) concluyeron que dicho impacto estaba determinado por el gasto público en capital humano $e$ infraestructura física.

Fuentes (2003) encontró que el crecimiento estaba determinado por las particularidades propias de cada región al analizar mediante técnicas econométricas cómo la inversión pública incide en la generación de sus ingresos propios. Así mismo, en un intento por evidenciar el cumplimiento de la Ley de Wagner en Argentina, Brasil, España y México, Díaz \& Revuelta (2009), mediante la combinación de modelos de corrección de error, técnicas de integración y de causalidad, descubrieron que en efecto este planteamiento se cumple en extenso para todos los países estudiados, así mismo confirmaron 
no sólo esta relación para América Latina sino la hipótesis keynesiana en España para el periodo 1960-2000.

En otro estudio, Sánchez (2006) al analizar si el crecimiento de la economía colombiana es balanceado entre los 25 departamentos que tomó como muestra para el periodo 1975-1998, encontró que el sector servicios no sólo era el más activo sino el que mayor grado de asociación inter sectorial se originó entre las regiones. Por su parte, Cedillo (2007), Necib \& Zakane (2009), bajo el enfoque de crecimiento endógeno, concluyeron que el gasto público en la promoción de capital humano e investigación y desarrollo promueven la innovación de productos y/o conceptos representativos del progreso tecnológico que indudablemente dinamizan la economía e impactan el nivel de producto, siendo por tanto, factores definitivos en el crecimiento regional.

Posteriormente Perilla (2012), profundizando el trabajo de Gómez \& Posada (2003) revisó para el periodo 2005-2010 el efecto de los servicios de capital en la formación bruta de capital fijo por producto y sector, revelando que los beneficios de unos y otros a la producción representan fuentes importantes de crecimiento económico.

El trabajo más reciente de Mendoza \& Yanes (2014) estudia el impacto que tiene el gasto y la inversión públicas en el crecimiento económico de los departamentos en Colombia, utilizando los resultados de las cuentas nacionales para el periodo 2000-2011; sus resultados evidenciaron una influencia fuerte del gasto público en el PIB regional mientras que la formación bruta de capital fijo lo hace en menor proporción.

Las diferentes investigaciones descritas, entre otras, han pretendido determinar el efecto del gasto público en el crecimiento así como determinar los criterios de asignación regionales que se deben tener para que su incidencia sea efectiva en el comportamiento de la actividad económica. El debate académico sugiere que no existe una manera única de describir el origen de tal influencia, ni cuál de estos agregados es el que determina los efectos sobre el otro. Para hacer un aporte a esta discusión, se ha desarrollado una línea de trabajo orientada a identificar en qué medida se presentan dichos impactos y como se propicia su encadenamiento en la dinámica productiva. En tal sentido, el problema de investigación a resolver con este trabajo consiste en representar como ha sido el impacto del gasto público en el PIB departamental y el aporte de las diferentes regiones al total para el periodo 20002013, mediante la identificación de algunas particularidades de dicho impacto, de manera que se describa en qué sentido esta asignación es eficiente o no para las regiones.

Este trabajo es fruto del análisis de los resultados obtenidos mediante la combinación de diferentes técnicas de inferencia y análisis de información que incluyen indicadores derivados de la econometría, otros orientados a determinar la contribución efectiva de diferentes modalidades de gasto público al interior de grupos regionales, así como indicadores de ubicación geográfica y desempeño fiscal del gasto, de manera que en su conjunto permitan describir la postura fiscal de sus gobiernos para incidir en la actividad económica. Para ello, se utilizaron las series de las cuentas departamentales ${ }^{1}$, así como un conjunto importante de estadísticas fiscales oficiales compuesto por los resultados desagregados de las ejecuciones presupuestales de los departamentos y la estructura completa de componentes del indicador de desempeño fiscal ${ }^{2}$.

De manera general, la metodología adoptada consistió en desarrollar un modelo básico MCO orientado a revelar el grado de asociación de las variables, el cual se complementa con el análisis de las contribuciones relativas al crecimiento de diferentes variables de actividad y del gasto público, construcción de indicadores de localización y/o especialización productiva así como de desempeño fiscal, como ele-

\footnotetext{
Cuyos resultados se construyen con base en el estándar internacionalmente reconocido del Sistema de Cuentas Nacionales de 1993 y 2008 de la Organización de Naciones Unidas y son elaborados por el Departamento Administrativo Nacional de Estadística - DANE.

2 Su metodología y series son compilados y elaborados por el Departamento Nacional de Planeación a partir de lo contemplado en el decreto ley 111 de 1996 y la ley 617 de 2000, respectivamente.
} 
mentos que apoyen la comprobación del supuesto según el cual la eficiencia del gasto público en las regiones tendría incidencia en el crecimiento de su PIB. Durante el proceso de elaboración se profundizó en técnicas de medición aún no exploradas en el ámbito de la contabilidad nacional regional en Colombia con el fin de propender por el uso aplicado de estas estadísticas en el análisis del impacto del gasto público en la dinámica económica de los departamentos que componen los grupos focales que se conformaron para este estudio.

El documento está dividido de la siguiente manera: En la primera parte se describe la metodología utilizada, explicando el diseño de los procedimientos y aplicación de los instrumentos utilizados para analizar el problema planteado. En la segunda parte se ilustran los diferentes resultados obtenidos de la investigación, contrastando cada fase del trabajo con la evidencia obtenida; por último, se abre la discusión, describiendo las conclusiones derivadas en cada una de las etapas del trabajo y apoyando los hallazgos con diferentes investigaciones que señalan la caracterización de los vínculos entre gasto público y crecimiento económico.

\section{Metodología}

Con base en estos importantes precedentes y con el fin de determinar el impacto efectivo del gasto público en el crecimiento de los departamentos se adoptó una metodología con enfoque multimodal, cuya primera fase combina técnicas de MCO para identificar la relación existente entre el gasto y la inversión públicos con el crecimiento económico según los grupos de economías regionales constituidos. En tal sentido, se planteó un modelo que responde a la siguiente descripción:

$\mathrm{PIB}_{\mathrm{ij}}=\mathrm{PIB}_{\mathrm{ij}}=\beta_{0}+\beta_{1} \mathrm{G}_{\mathrm{ij}}+\mathrm{E}_{\mathrm{ij}}$

Donde:

PIB $_{\mathrm{ij}}$ : PIB del departamento $\mathrm{j}$ en el periodo $\mathrm{i}$

$G_{i j}$ : Gasto público del departamento j en sus diferentes modalidades durante el periodo $\mathrm{i}$

$\beta_{0}, \beta_{1}=$ Representan los parámetros del modelo y, $\mathrm{E}_{\mathrm{ij}}$ : es el término del error.
Con el propósito de facilitar el procesamiento y análisis de los datos departamentales (incluido Bogotá), las regiones se organizaron en una tríada jerárquica en la que cada grupo está conformado con igual número de integrantes de conformidad con la participación media que sus valores agregados presentaron durante el periodo de estudio (2000-2013) ${ }^{3}$, lo cual determinó la conformación de los siguientes conjuntos de departamentos que se denominarán en lo sucesivo grupos-región, así:

- Economías principales: Bogotá, Antioquía, Valle, Santander, Cundinamarca, Atlántico, Bolívar, Meta, Boyacá, Tolima y Casanare.

- Economías intermedias: Córdoba, Huila, Cesar, Norte de Santander, Caldas, Nariño, Risaralda, Cauca, Magdalena, La Guajira y Arauca.

- Economías pequeñas: Quindío, Sucre, Caquetá, Chocó, Putumayo, San Andrés y Providencia, Guaviare, Amazonas, Vichada, Guainía y Vaupés ${ }^{4}$.

Este modelo fue aplicado a los resultados totales del gasto público y el PIB regional para los gruposregión, así como para cada uno de sus integrantes a fin de identificar el grado de asociación lineal existente entre las variables de análisis durante el periodo de estudio ${ }^{5}$. De otro lado, en la medida que el crecimiento de una variable, llámese $\mathrm{X}$, puede expresarse como la suma de las contribuciones relativas de sus elementos constitutivos, estos aportes se obtienen como resultado del producto entre la ponderación de cada variable en el total agregado al que pertenece (calculado en el año anterior) y su variación porcentual, lo cual se expresa como:

$\mathrm{C}\left(\mathrm{x}_{\mathrm{i}} / \mathrm{X}\right)_{\mathrm{n}}=\mathrm{W}_{\mathrm{xin}-1} *\left[\left(\mathrm{X}_{\mathrm{in}}-\mathrm{X}_{\mathrm{in}-1}\right) /\left(\mathrm{X}_{\mathrm{in}-1}\right)\right]$

Para dicho trabajo se analizaron los resultados de las cuentas nacionales departamentales de Colombia para el periodo 2000-2013 actualizados a la fecha.

4 La conformación de los grupos-región siguió los mismos protocolos definidos por Mendoza \& Yanes (2014).

5 Los autores reconocen las limitaciones en el alcance del modelo originadas por la no disponibilidad de series de producto interno bruto departamental más largas, no obstante toman estos resultados como punto de partida de los análisis complementarios señalados a lo largo del documento. 
Donde:

$\mathrm{C}\left(\mathrm{x}_{\mathrm{i}} / \mathrm{X}\right)_{\mathrm{n}}$ : Contribución de la variable $\mathrm{Xi}$ al crecimiento total de $\mathrm{X}$ en el periodo $\mathrm{n}$

$\mathrm{W}_{\text {xin-1 } 1}$ : Ponderación de $\mathrm{X}$ para el individuo i en el total de la variable $\mathrm{X}$ durante el año inicial de referencia

$\left[\left(\mathrm{X}_{\mathrm{in}}-\mathrm{X}_{\mathrm{in}-1}\right) /\left(\mathrm{X}_{\mathrm{in}-1}\right)\right]$ : Tasa de crecimiento de la variable $\mathrm{X}$ para el individuo i con relación al periodo anterior

Es así como los resultados aportados en la primera fase son contrastados con el estudio de la contribución efectiva intertemporal del producto del gobierno al PIB departamental y total nacional en cada grupo analizado, a partir de la medición de los aportes a la variación del PIB de cada grupo-región así como de sus integrantes.

Como elemento de contraste de estas contribuciones y con el fin de identificar la ubicación estratégica regional del gasto público, se recrearon coeficientes técnicos de localización geográfica mediante los cuales se identifica la importancia relativa de una actividad o variable en un departamento de interés, en contraste a como dicho evento está representado en una región más grande o el total del país. Por tanto, el coeficiente CLx ${ }_{i j}$ se define como:

$$
C L x_{i j}=\frac{x_{i j} / \sum_{i j} x_{i j}}{\sum_{k} x_{i} / \sum_{h} \sum_{k} x_{i}}
$$

Donde:

$\mathrm{X}_{\mathrm{ij}}$, con $(\mathrm{i}=1,2, \ldots \mathrm{h})$ identifica las variables económicas de interés (gasto, producto, público, formación bruta de capital fijo, etc.) en cada una de las regiones de análisis $(\mathrm{j}=1,2, \ldots \mathrm{k})$ o departamentos; $\sum_{\mathrm{ij}} \mathrm{X}_{\mathrm{ij}}$ representa el valor total del fenómeno $\mathrm{X}_{\mathrm{i}}$ a analizar en el total en la región $\mathrm{j} ; \Sigma_{\mathrm{k}}$ identifica el valor de la variable $\mathrm{X}_{\mathrm{i}}$ en el total del país y $\sum_{\mathrm{h}} \sum_{\mathrm{k}}$ corresponde a total de la variable analizada $\mathrm{X}_{\mathrm{i}}$ en el total del país.

De lo anterior se colige que si:

$C L x_{i j}>1$, la región observada presenta mayor especialización en la actividad Xi que el resto del país. $C L x_{i j}<1$, la región observada presenta menor especialización en la actividad Xi que el resto del país. $C L x_{i j}=1$, la región observada presenta igual espe- cialización en la variable Xi que el resto del país.

Con estos criterios considerados, las contribuciones relativas al crecimiento son matizadas a nivel regional con el coeficiente de localización geográfica del PIB del gobierno a fin de caracterizar su dinámica e impacto tomando como referente el valor agregado departamental y nacional. Este ejercicio se hizo extensivo en la identificación de la ubicación relativa del gasto público total y de infraestructura en los grupos-región constituidos a fin de determinar las regiones con mayor/menor influencia de estos agregados ${ }^{6}$.

Finalmente, de conformidad con lo establecido en la ley 617 de 2000 los anteriores resultados se analizan en contexto con el desempeño fiscal de los departamentos durante el periodo de estudio. Para esta última fase, se tabularon y promediaron los resultados por departamento y grupo-región de cada uno de los componentes del Indicador de Desempeño Fiscal - IDF ${ }^{7}$ departamental (incluido Bogotá) para el periodo 2000-2013 identificando a partir de este los factores que han incidido en el comportamiento del gasto de estas regiones, evaluando su capacidad para influir significativamente en su crecimiento económico.

\section{Resultados}

El análisis de resultados se cubre desde diferentes ópticas: De una parte se revisan los resultados de asociación entre el gasto público y el PIB en cada grupo-región mediante el modelo MCO, cuya rela-

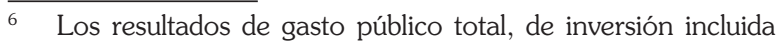
la formación bruta de capital fijo y demás referentes de gasto fueron tomados de las ejecuciones presupuestales de los departamentos publicadas por el departamento nacional de planeación disponibles en su página de internet https:// pwh.dnp.gov.co/Programas/DesarrolloTerritorial/Finanzas P\%C3\%BAblicasTerritoriales/EjecucionesPresupuestales. aspx, recuperados en octubre de 2014.

7 Estos resultados son producidos por el Departamento Nacional de Planeación cada año en atención a lo establecido por la Ley 617 de 2000. La serie 2000-2013 corresponde a los resultados más recientes publicados por dicha entidad y disponibles en su página de internet https://www.dnp.gov. $\mathrm{co} /$ programas/desarrollo-territorial/evaluacion-y-seguimiento-de-la-descentralizacion/Paginas/desempeno-fiscal.aspx, recuperados en octubre de 2014. 
ción se complementa identificando el aporte relativo al crecimiento regional del producto público, el gasto total y la formación bruta de capital. Finalmente, mediante la descripción de los resultados de indicadores específicos de localización regional del gasto público contrastados con el desempeño fiscal de las regiones a lo largo de la serie, permitirán describir la naturaleza de la influencia del sector público durante el periodo de estudio.

Los resultados muestran una incidencia importante del gasto público en el PIB de las economías principales, intermedias y pequeñas para el periodo de estudio (Tabla 1), medición que, para ser caracterizada, se efectuó también para cada uno de los departamentos que conforman cada grupo-región.
Dicha relación resultó también ser significativa al analizar en cada caso y por separado la influencia de la inversión social, la formación bruta de capital y los gastos corrientes en la dinámica productiva correspondiente.

Como se aprecia en la Tabla 2 en todos los departamentos del grupo, excepto Casanare, el gasto público incidió en el producto departamental, destacándose la influencia que este tiene en Bolívar, Antioquia y Bogotá, principalmente. Por otra parte, al revisar los aportes al PIB nacional de este grupo-región se aprecia que estos representaron el $79,9 \%$ de los puntos porcentuales en juego y sus economías crecieron en promedio $9,5 \%{ }^{8}$ durante el periodo 2000-2013 (Tabla 3).

Tabla 1. Economías Principales, Intermedias y Pequeñas: Indicadores básicos MCO relación Gasto Público-PIB9

\begin{tabular}{lccccc}
\hline \multicolumn{1}{c}{ Descripción } & Correlación múltiple & Coeficiente de determinación R2 & R2 ajustado & Error típico & Observaciones \\
\hline Principales & 0,968 & 0,936 & 0,931 & 35.236 & 14 \\
Intermedias & 0,994 & 0,988 & 0,904 & 8.888 & 14 \\
Pequeñas & 0,956 & 0,914 & 0,907 & 1.791 & 14 \\
\hline
\end{tabular}

Fuente: Cálculos propios con base en información de DANE y DNP.

Tabla 2. Economías Principales: Indicadores básicos MCO relación PIB-gasto público

\begin{tabular}{lcccc}
\hline Departamento & Correlación múltiple & R2 & R2 ajustado & Error típico \\
\hline Bolívar & 0,977 & 0,955 & 0,951 & 1.58 \\
Antioquia & 0,974 & 0,949 & 0,945 & 4.947 \\
Bogotá & 0,965 & 0,932 & 0,926 & 10.8 \\
Tolima & 0,948 & 0,899 & 0,891 & 1.154 \\
C/marca & 0,942 & 0,887 & 0,877 & 2.875 \\
Atlántico & 0,94 & 0,884 & 0,874 & 2.105 \\
Boyacá & 0,894 & 0,8 & 0,783 & 2.291 \\
Santander & 0,889 & 0,791 & 0,774 & 6.476 \\
Valle & 0,842 & 0,708 & 0,684 & 8.102 \\
Meta & 0,839 & 0,704 & 0,679 & 7.564 \\
Casanare & 0,255 & 0,065 & $-0,013$ & 3.45 \\
\hline
\end{tabular}

Fuente: Cálculos propios con base en información de DANE y DNP.

8 Este resultado corresponde a la media geométrica del crecimiento del PIB de este grupo-región. Este mismo indicador se utilizó en el caso de las economías intermedias y pequeñas. 
Tabla 3. Aporte de las economías principales, intermedias y pequeñas al crecimiento del PIB total de Colombia (2001-2013)

\begin{tabular}{ccccc}
\hline Descripción & Principales & Intermedias & Pequeñas & Colombia \\
\hline 2001 & 6,6 & 1,4 & 0,3 & 8,3 \\
2002 & 6,6 & 1,8 & 0,2 & 8,6 \\
2003 & 8,8 & 2,0 & 0,2 & 11,0 \\
2004 & 10,2 & 2,5 & 0,4 & 13,0 \\
2005 & 8,1 & 2,1 & 0,3 & 10,5 \\
2006 & 10,1 & 2,3 & 0,5 & 12,9 \\
2007 & 10,1 & 1,8 & 0,3 & 12,3 \\
2008 & 8,8 & 2,2 & 0,4 & 11,4 \\
2009 & 4,0 & 0,8 & 0,3 & 5,1 \\
2010 & 6,8 & 0,9 & 0,3 & 8,0 \\
2011 & 11,4 & 1,9 & 0,5 & 13,8 \\
2012 & 6,0 & 1,1 & 0,3 & 7,3 \\
2013 & 5,2 & 0,8 & 0,2 & 6,3 \\
Contribución & 102,6 & 21,7 & 4,2 & 128,5 \\
intertemporal & & & & \\
(puntos\%) & & 16,9 & 3,2 & 100,0 \\
Peso (\%) contri- & 79,9 & & & \\
bución al PIB & & & & \\
\hline
\end{tabular}

Fuente: Cálculos propios con base en las Cuentas Departamentales a precios de mercado del DANE.

Las economías intermedias aportaron al PIB nacional el $16,9 \%$ de puntos porcentuales de crecimiento y su producto aumentó en promedio $9,2 \%$ a lo largo del periodo 2000-2013, algo menos que las economías principales. En este grupo-región puede así mismo apreciarse una significativa influencia del gasto público en el PIB, principalmente por los resultados presentados en Nariño, Cauca y Magdalena y aunque algo menor, Huila y Arauca (Tabla 4).

Todas las economías pequeñas con excepción de Guaviare manifestaron una relación significativa entre el gasto público y el PIB de su región, principalmente por los resultados de Sucre, Quindío y Vaupés (Tabla 5). Sin embargo el PIB total de este gruporegión representó sólo el 3,2\% de los puntos porcentuales de crecimiento al producto nacional, que si bien parece pequeño, no es insignificante en la medida que para las economías de este grupo-región su PIB creció al mismo ritmo de las economías principales $(9,5 \%$ en promedio) en buena parte gracias al impulso otorgado por el gasto público, aunque por su tamaño, la contribución a la dinámica productiva resulta marginal durante los últimos 14 años.

Tabla 4. Economías Intermedias Indicadores básicos MCO relación PIB-gasto público

\begin{tabular}{lcccc}
\hline Departamento & $\begin{array}{c}\text { Correlación } \\
\text { múltiple }\end{array}$ & R2 & R2 ajustado & Error típico \\
\hline Nariño & 0,979 & 0,959 & 0,955 & 41,5 \\
Cauca & 0,965 & 0,932 & 0,926 & 60,6 \\
Magdalena & 0,961 & 0,924 & 0,917 & 53,6 \\
Norte Santander & 0,96 & 0,922 & 0,916 & 51,7 \\
Caldas & 0,95 & 0,902 & 0,894 & 37,8 \\
Cesar & 0,928 & 0,86 & 0,849 & 92,5 \\
Córdoba & 0,91 & 0,829 & 0,815 & 107,2 \\
Risaralda & 0,908 & 0,824 & 0,809 & 30,4 \\
Guajira & 0,853 & 0,727 & 0,705 & 107,3 \\
Huila & 0,845 & 0,715 & 0,691 & 104,8 \\
Arauca & 0,839 & 0,703 & 0,678 & 104,1 \\
\hline
\end{tabular}

Fuente: Cálculos propios con base en las Cuentas Departamentales a precios de mercado del DANE.

Tabla 5. Economías Pequeñas Indicadores básicos MCO relación PIB-gasto público

\begin{tabular}{lcccc}
\hline Departamento & $\begin{array}{c}\text { Correlación } \\
\text { múltiple }\end{array}$ & R2 & R2 ajustado & Error típico \\
\hline Sucre & 0,944 & 0,89 & 0,881 & 441,1 \\
Quindío & 0,935 & 0,875 & 0,864 & 416,6 \\
Vaupés & 0,913 & 0,834 & 0,82 & 16,0 \\
Amazonas & 0,891 & 0,795 & 0,777 & 46,9 \\
San Andrés & 0,854 & 0,729 & 0,707 & 121,7 \\
Guainía & 0,854 & 0,729 & 0,706 & 29,2 \\
Vichada & 0,844 & 0,713 & 0,689 & 48,9 \\
Putumayo & 0,842 & 0,708 & 0,684 & 686,1 \\
Caquetá & 0,83 & 0,689 & 0,663 & 412,0 \\
Chocó & 0,817 & 0,668 & 0,64 & 574,4 \\
Guaviare & 0,592 & 0,35 & 0,296 & 109,3 \\
\hline
\end{tabular}

Fuente: Cálculos propios con base en información de DANE y DNP. 
En estos resultados se destaca el comportamiento del gasto público total que creció $10,1 \%$ en promedio para el periodo $2000-2013$ y $28,9 \%$ en el último año, aumentando en promedio en las economías pequeñas, intermedias y principales en $14,4 \%$, $13,1 \%$ y $9,1 \%$, respectivamente siendo el año 2013 en la mayoría de los casos, la vigencia con mayor ejecución fiscal en las regiones. De este componente, la formación bruta de capital fijo, referente de la inversión productiva y que impacta el crecimiento económico vía demanda, ha tenido un comportamiento irregular en los grupos-región aunque particularmente en los últimos años del periodo 2000-
2013 se intensificó en las regiones, principalmente en las economías de menor tamaño (Tabla 6).

Durante el periodo observado, la inversión pública tuvo mayor participación en las economías intermedias y pequeñas que en las grandes. Para estas regiones el gasto público constituye el elemento dinamizador de su estructura productiva, particularmente por la orientación que ha tenido en torno al fortalecimiento de la infraestructura en obras civiles y la intensificación que ha venido presentando la actividad edificadora (Ilustración 1).

Tabla 6. Variación porcentual conceptos de gasto público por grupo-región (2000-2013)

\begin{tabular}{|c|c|c|c|c|c|c|c|c|c|c|c|c|c|c|}
\hline $\begin{array}{l}\text { Descripción/ } \\
\text { Región }\end{array}$ & & $\begin{array}{l}2001 \\
/ 2000\end{array}$ & $\begin{array}{l}2002 / \\
2001\end{array}$ & $\begin{array}{l}2003 / \\
2002 \\
\end{array}$ & \begin{tabular}{l|}
2004 \\
$/ 2003$
\end{tabular} & $\begin{array}{l}2005 / \\
2004\end{array}$ & $\begin{array}{l}2006 \\
/ 2005\end{array}$ & $\begin{array}{l}2007 / \\
2006\end{array}$ & $\begin{array}{l}2008 \\
\text { / } 2007\end{array}$ & $\begin{array}{l}2009 / \\
2008\end{array}$ & $\begin{array}{l}2010 \\
/ 2009\end{array}$ & $\begin{array}{l}2011 \\
/ 2010\end{array}$ & $\begin{array}{l}2012 \\
/ 2011\end{array}$ & $\begin{array}{l}2013 / \\
2012\end{array}$ \\
\hline 1. GASTO TOTAL & \multirow{4}{*}{ 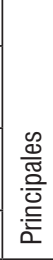 } & $(7,2)$ & 18,3 & 4,4 & 5,8 & 25,6 & 19,0 & 11,4 & $(0,9)$ & 11,6 & 15,3 & 0,5 & $(8,8)$ & 22,9 \\
\hline $\begin{array}{c}1.1 \text { GASTO } \\
\text { CORRIENTE }\end{array}$ & & $(5,8)$ & 12,6 & 2,6 & 11,4 & 1,0 & 10,0 & 18,2 & 13,7 & 6,2 & 5,0 & 7,7 & $(0,7)$ & 4,7 \\
\hline $\begin{array}{l}\text { 1.2 GASTO DE } \\
\text { CAPITAL }\end{array}$ & & $(7,7)$ & 20,3 & 5,0 & 4,0 & 34,2 & 21,3 & 9,8 & $(4,7)$ & 13,3 & 18,3 & $(1,3)$ & $(11,1)$ & 28,6 \\
\hline 1.2.1 FBKF* & & $(47,6)$ & 72,0 & 44,7 & $(33,6)$ & 70,3 & 71,7 & 22,2 & $(19,4)$ & $(4,5)$ & 38,2 & $(5,1)$ & $(11,1)$ & 42,4 \\
\hline 1. GASTO TOTAL & \multirow{4}{*}{ 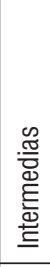 } & 11,5 & 21,6 & 5,0 & 13,0 & 25,8 & 13,0 & 19,6 & 0,7 & 18,5 & 9,6 & 6,1 & $(20,4)$ & 45,6 \\
\hline $\begin{array}{l}1.1 \text { GASTO } \\
\text { CORRIENTE }\end{array}$ & & 13,9 & 11,6 & 8,0 & $(0,7)$ & $(12,5)$ & 19,8 & 16,4 & 15,9 & 12,1 & 10,2 & 9,2 & $(7,7)$ & 27,8 \\
\hline $\begin{array}{l}1.2 \mathrm{GASTO} \text { DE } \\
\text { CAPITAL }\end{array}$ & & 10,9 & 24,0 & 4,4 & 16,0 & 33,0 & 12,2 & 20,0 & $(1,2)$ & 19,4 & 9,5 & 5,7 & $(22,2)$ & 48,7 \\
\hline 1.2.1 FBKF* & & $(12,6)$ & 161,9 & 99,2 & $(30,0)$ & 49,2 & 99,4 & 69,8 & $(28,1)$ & 27,5 & $(2,0)$ & 20,9 & $(59,2)$ & 229,6 \\
\hline 1. GASTO TOTAL & \multirow{4}{*}{ 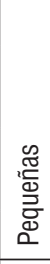 } & 17,8 & 50,6 & $(9,2)$ & 22,8 & 15,3 & 12,5 & 14,1 & $(0,9)$ & 15,6 & 2,7 & 10,1 & $(7,7)$ & 43,1 \\
\hline $\begin{array}{l}1.1 \text { GASTO } \\
\text { CORRIENTE } \\
\end{array}$ & & $(3,1)$ & 34,3 & 36,4 & $(38,6)$ & 1,2 & 20,3 & 21,8 & 7,6 & 42,1 & $(11,6)$ & 18,3 & $(1,1)$ & 29,4 \\
\hline $\begin{array}{l}1.2 \text { GASTO DE } \\
\text { CAPITAL }\end{array}$ & & 24,3 & 54,5 & $(18,8)$ & 44,6 & 17,4 & 11,5 & 13,0 & $(2,2)$ & 11,1 & 5,8 & 8,6 & $(8,9)$ & 46,0 \\
\hline 1.2.1 FBKF* & & $(38,3)$ & 610,3 & $(49,1)$ & 37,4 & 14,2 & 130,9 & 56,0 & $(9,8)$ & $(30,9)$ & 14,5 & 11,8 & $(35,9)$ & 235,2 \\
\hline 1. GASTO TOTAL & \multirow{4}{*}{ 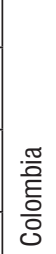 } & $(2,8)$ & 20,9 & 3,5 & 8,4 & 24,8 & 17,3 & 13,3 & $(0,5)$ & 13,4 & 13,2 & 2,3 & $(11,4)$ & 28,9 \\
\hline $\begin{array}{l}1.1 \text { GASTO } \\
\text { CORRIENTE }\end{array}$ & & $(3,1)$ & 13,5 & 5,4 & 5,8 & $(0,9)$ & 11,7 & 18,1 & 13,7 & 8,7 & 4,7 & 8,5 & $(1,7)$ & 9,3 \\
\hline $\begin{array}{l}1.2 \text { GASTO DE } \\
\text { CAPITAL }\end{array}$ & & $(2,6)$ & 23,3 & 3,0 & 9,2 & 32,5 & 18,5 & 12,2 & $(3,7)$ & 14,6 & 15,3 & 1,0 & $(13,7)$ & 34,3 \\
\hline 1.2.1 FBKF* & & $(45,5)$ & 90,5 & 44,5 & $(31,2)$ & 63,8 & 78,1 & 32,0 & $(20,8)$ & 0,4 & 26,8 & 0,8 & $(23,7)$ & 73,4 \\
\hline
\end{tabular}

Fuente: Construcción propia basado en ejecuciones presupuestales regionales - DNP.

* Formación bruta de capital fijo. 
Por otra parte, como proporción del gasto total, la formación bruta de capital fijo (FBKf) de las economías principales supera hoy día la media nacional, siendo igualmente superior a la de las regiones pequeñas e intermedias. A lo largo de la serie se ad- vierte cómo esta conducta ha venido orientando de manera progresiva la ejecución eficiente del gasto enfocándolo al fortalecimiento de las capacidades productivas regionales en los grupos-región analizados (Ilustración 2).

Ilustración 1. Cociente gasto inversión/gasto total por grupos-región (2000-2013)

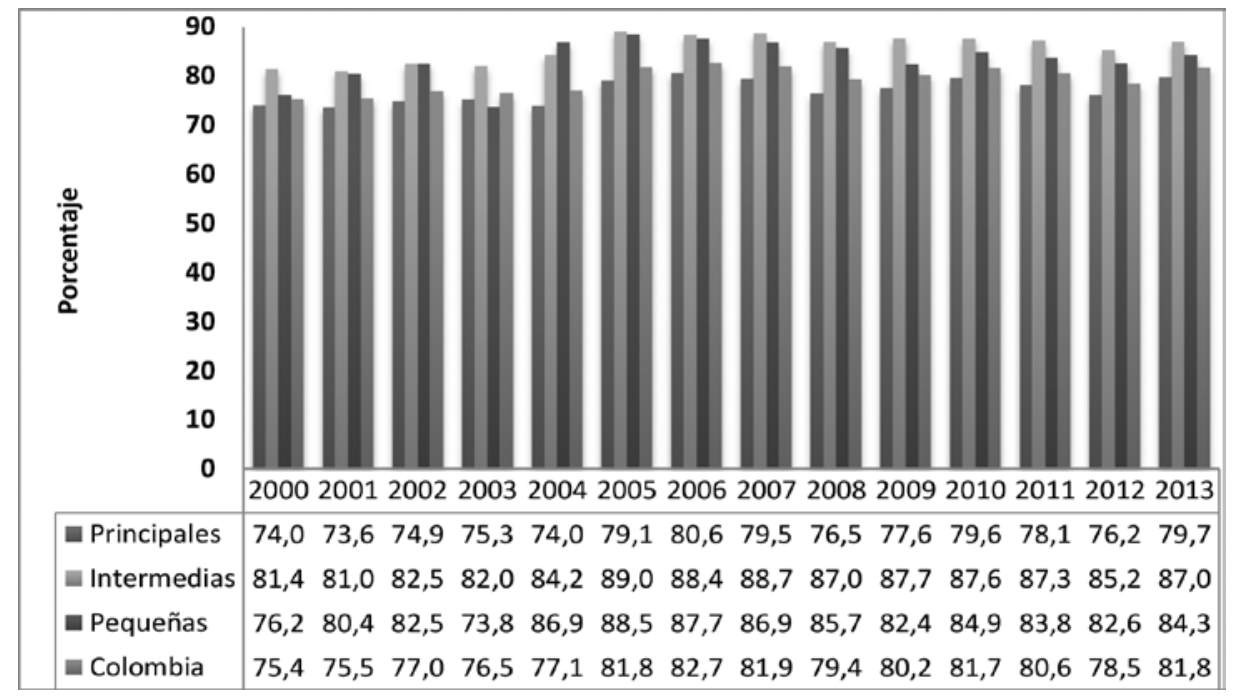

Fuente: Construcción propia basado en ejecuciones presupuestales regionales - DNP y las cuentas departamentales del DANE.

Ilustración 2. Cociente formación bruta de capital fijo / gasto total por grupos-región (2000-2013)

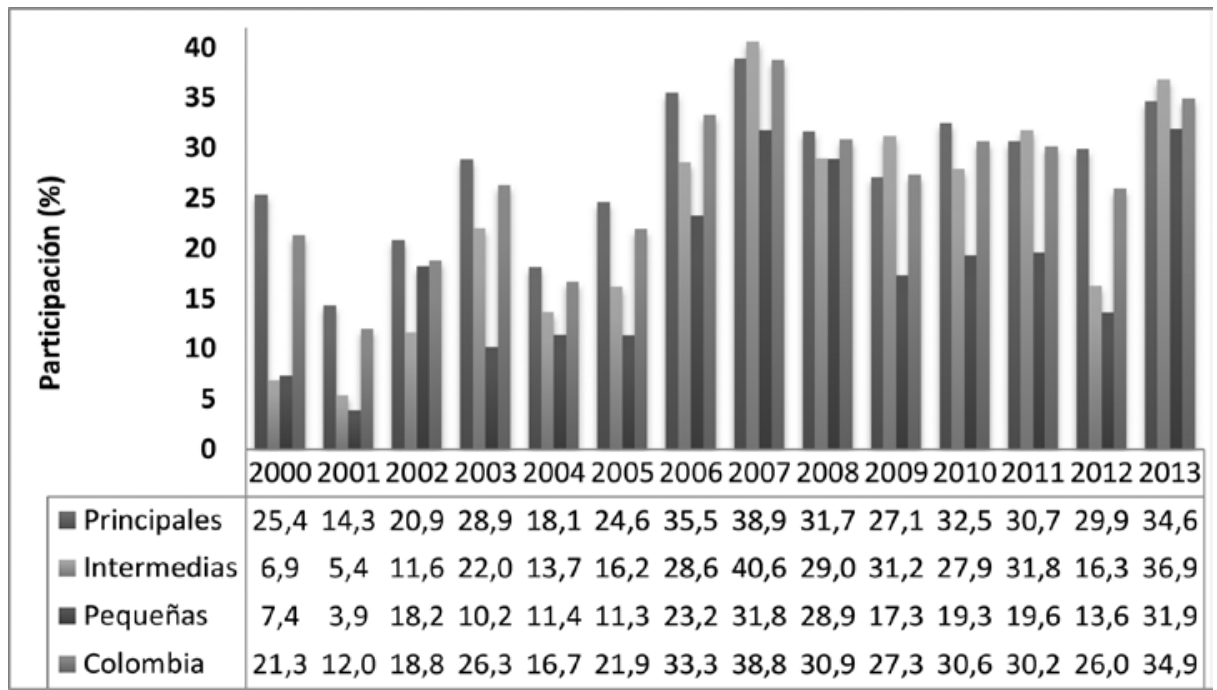

Fuente: Construcción propia basado en ejecuciones presupuestales regionales - DNP y las cuentas departamentales del DANE. 
Sin embargo, la participación media de la FBKf en el PIB total de las economías pequeñas está por encima de la media nacional, superando ligeramente a la de principales e intermedias, lo cual evidencia que el Estado en este grupo-región está otorgando cada vez más mayor relevancia a la construcción de infraestructura para fortalecer la capacidad produc- tiva, en especial por la dinámica presentada durante los años 2007 y 2013 y cuyo efecto se expresa mediante la evaluación del aporte relativo de estos agregados al PIB por cada grupo-región, en los que las economías pequeñas aportaron más puntos al crecimiento de su región que los efectuados por las economías intermedias y grandes (Tabla 7).

Tabla 7. Aporte relativo del gasto total y la formación bruta de capital fijo-FBKf al PIB de cada grupo -región (2000-2013)

\begin{tabular}{ccccccccc}
\hline Grupo Región & \multicolumn{2}{c}{ Principales } & \multicolumn{2}{c}{ Intermedias } & \multicolumn{2}{c}{ Pequeñas } & \multicolumn{2}{c}{ Colombia } \\
\hline Concepto de Gasto & Gasto total & FBKf & Gasto total & FBKf & Gasto total & FBKf & Gasto total & FBKf \\
\hline 2001 & $(0,4)$ & $(0,6)$ & 0,6 & $(0,0)$ & 1,3 & $(0,2)$ & $(0,1)$ & $(0,5)$ \\
2002 & 0,8 & 0,4 & 1,2 & 0,5 & 4,1 & 1,9 & 1,0 & 0,5 \\
2003 & 0,2 & 0,4 & 0,3 & 0,7 & $(1,1)$ & $(1,0)$ & 0,2 & 0,4 \\
2004 & 0,3 & $(0,4)$ & 0,7 & $(0,4)$ & 2,3 & 0,4 & 0,4 & $(0,4)$ \\
2005 & 1,0 & 0,5 & 1,4 & 0,4 & 1,7 & 0,2 & 1,1 & 0,5 \\
2006 & 0,9 & 0,8 & 0,8 & 1,0 & 1,4 & 1,7 & 0,9 & 0,9 \\
2007 & 0,6 & 0,4 & 1,2 & 1,2 & 1,6 & 1,4 & 0,7 & 0,6 \\
2008 & $(0,0)$ & $(0,4)$ & 0,1 & $(0,8)$ & $(0,1)$ & $(0,4)$ & $(0,0)$ & $(0,4)$ \\
2009 & 0,5 & $(0,1)$ & 1,1 & 0,5 & 1,6 & $(0,9)$ & 0,6 & 0,0 \\
2010 & 0,7 & 0,5 & 0,7 & $(0,0)$ & 0,3 & 0,3 & 0,7 & 0,4 \\
2011 & 0,0 & $(0,1)$ & 0,4 & 0,4 & 1,0 & 0,2 & 0,1 & 0,0 \\
2012 & $(0,4)$ & $(0,1)$ & $(1,4)$ & $(1,3)$ & $(0,7)$ & $(0,7)$ & $(0,6)$ & $(0,3)$ \\
2013 & 0,8 & 0,5 & 2,3 & 1,9 & 3,5 & 2,6 & 1,2 & 0,8 \\
\hline
\end{tabular}

Fuente: Construcción propia basado en ejecuciones presupuestales regionales - DNP y las cuentas departamentales (DANE).

Las restricciones en la diversificación productiva regional colombiana que concentra en las economías principales los mayores niveles de producto, sigue siendo un obstáculo para que la postura fiscal de las pequeñas economías garantice un crecimiento de su PIB superior al de los grupos región intermedios y grandes, pues si bien el gasto público y la FBKF presentaron un aporte relativo mayor al de los otros dos grupos al igual como lo respalda la contribución del valor agregado de sus gobiernos, su participación en el comportamiento del PIB nacional sigue estando muy alejada como referente del crecimiento. Así mismo, se observa como para el periodo de estudio y teniendo como 'Benchmark' el gasto público total del gobierno en Colombia $(1,0)$, la localización del gasto es mayor en las economías intermedias $(1,08)$ y pequeñas $(1,05)$ y por debajo de este en las economías principales $(0,97)$ lo que refleja una asignación equivalente en promedio del gasto en todas las regiones, a excepción de Valle $(0,86)$, Antioquia $(0,86)$ y San Andrés $(0,65)$, respectivamente que presentaron la menor postura fiscal geográfica (Ilustración 3).

En forma contraria, al analizar la dinámica geográfica de la formación bruta de capital fijo pública para el mismo lapso y con el mismo referente (Colombia con 1,0), la especialización fue superior en las economías principales $(1,08)$, en tanto que las intermedias $(0,82)$ y pequeñas $(0,64)$ crearon distancia importante por este concepto, siendo Casanare $(2,47)$, Arauca $(1,86)$, Meta $(1,81)$ y Guajira $(1,63)$, respectivamente los de mayor postura fiscal geográfica, en gran medida debido a la intensificación de la inversión en la exploración y explotación minera generada durante dicho periodo (Ilustración 4). 
Ilustración 3. Coeficiente de localización medio del gasto público departamental (2000-2013)

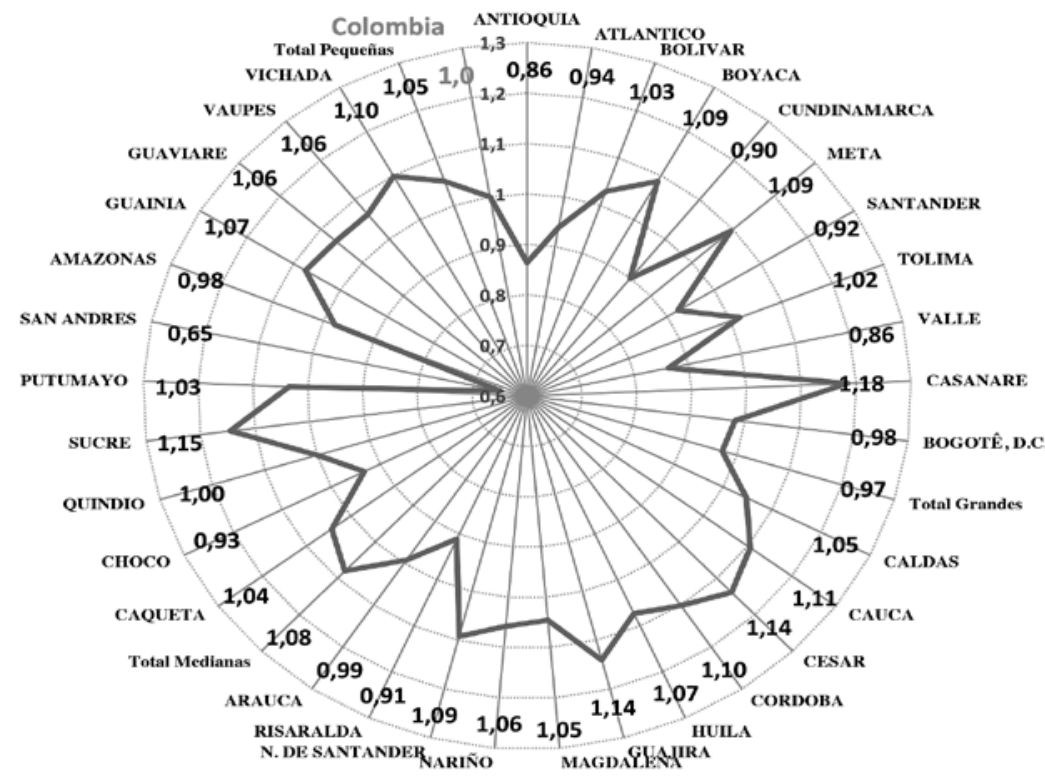

Fuente: Elaboración propia con base en las ejecuciones presupuestales de los departamentos - DNP.

Ilustración 4. Coeficiente de localización medio de la formación bruta de capital departamental (2000-2013)

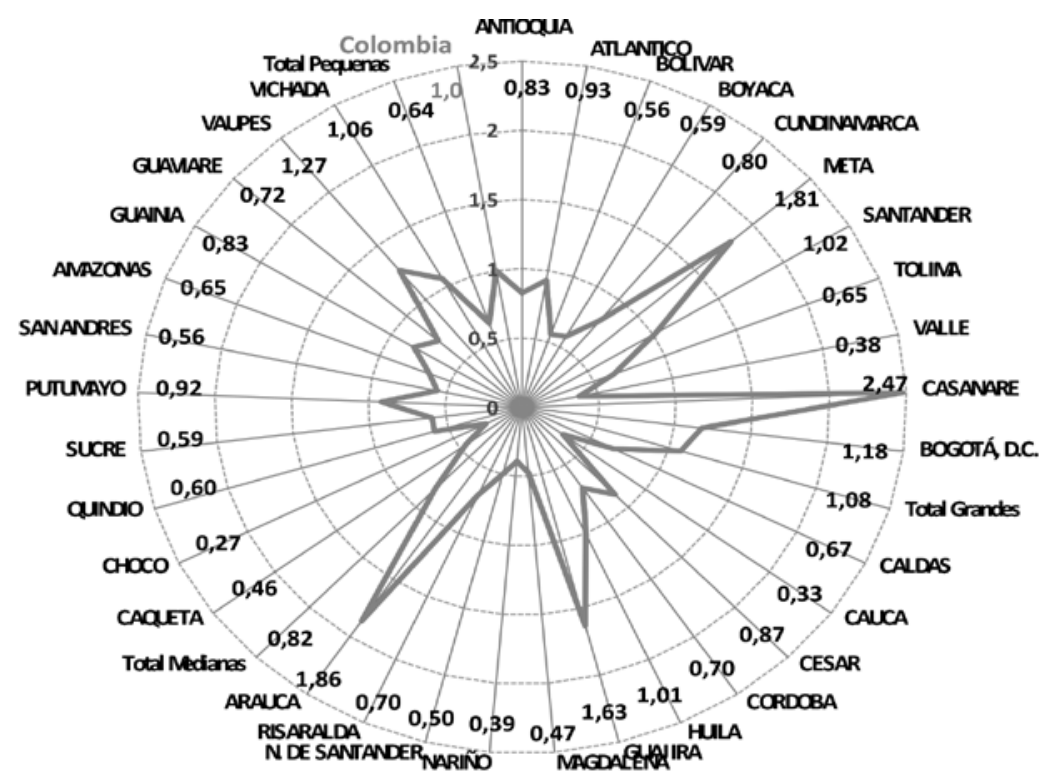

Fuente: Elaboración propia con base en las ejecuciones presupuestales de los departamentos - DNP.

Al analizar el coeficiente de localización geográfica del valor agregado del gobierno representando por la prestación de servicios de administración pública, se aprecia como ellos juegan un papel determinante en las economías pequeñas, al constituir en promedio el 22,3\% de su PIB durante el periodo 2000-2013, 
mientras que en las economías principales su peso promedio fue de 7,8\% y en las intermedias de $12,1 \%$. Lo anterior responde a la mayor diversificación productiva propia de las regiones principales y a que el sector público en las pequeñas constituye uno de los principales dinamizadores de su demanda (Tabla 8).

Tabla 8. Contribución del Valor Agregado del Gobierno Departamental en el PIB de su Departamento

\begin{tabular}{cccc}
\hline Descripción & Principales & Intermedias & Pequeñas \\
\hline 2001 & 0,4 & 1,5 & 2,1 \\
2002 & 0,8 & 1,3 & $-0,2$ \\
2003 & 0,5 & 1,4 & 2,2 \\
2004 & 1,0 & 1,3 & 3,9 \\
2005 & 0,7 & 1,2 & 1,9 \\
2006 & 0,6 & 1,3 & 1,8 \\
2007 & 0,9 & 1,3 & 2,0 \\
2008 & 0,8 & 1,6 & 3,3 \\
2009 & 0,9 & 1,2 & 2,4 \\
2010 & 0,7 & 1,1 & 1,5 \\
2011 & 0,6 & 1,1 & 1,7 \\
2012 & 0,7 & 1,3 & 2,4 \\
2013 & 0,7 & 1,3 & 1,9 \\
\hline Contribución efectiva & 9,3 & 17,0 & 26,7 \\
intertemporal & & &
\end{tabular}

Fuente: Construcción propia con base en las cuentas departamentales del DANE.

No obstante lo anterior, el PIB gubernamental de las economías principales pesa mucho más en el total del PIB del gobierno nacional $(69,4 \%)$, que el de las pequeñas economías $(8,1 \%)$ durante el periodo 2000-2013. En efecto, el valor agregado de los servicios del gobierno de las regiones más grandes aporta la mayor parte del crecimiento económico en el país en detrimento del aporte reducido que a este hacen las más pequeñas (Tabla 9).

En suma, puede apreciarse en la dinámica económica regional que la formación bruta de capital fijo y los servicios del gobierno aportaron proporcionalmente más al PIB de las economías pequeñas (ver casos de Vichada, Guainía, Vaupés) al incidir signi- ficativamente en su crecimiento, contrario a lo que sucedió en las economías principales, en las que si bien, su aporte geográfico es positivo, resultó ser mucho menor, en especial en los casos de Boyacá, Casanare y Meta (llustración 5).

Tabla 9. Aporte del PIB de los Gobiernos Departamentales en el PIB del Gobierno Nacional

\begin{tabular}{ccccc}
\hline Descripción & Principales & Intermedias & Pequeñas & Colombia \\
\hline 2001 & 3,4 & 2,6 & 0,8 & 6,8 \\
2002 & 6,6 & 2,2 & $-0,1$ & 8,7 \\
2003 & 4,3 & 2,6 & 0,8 & 7,6 \\
2004 & 8,9 & 2,4 & 1,3 & 12,6 \\
2005 & 6,1 & 2,3 & 0,7 & 9,1 \\
2006 & 5,6 & 2,5 & 0,6 & 8,7 \\
2007 & 8,2 & 2,6 & 0,7 & 11,5 \\
2008 & 7,1 & 3,2 & 1,2 & 11,6 \\
2009 & 8,1 & 2,4 & 0,9 & 11,4 \\
2010 & 6,2 & 2,1 & 0,6 & 8,9 \\
2011 & 5,4 & 2,0 & 0,6 & 8,0 \\
2012 & 6,7 & 2,5 & 0,9 & 10,1 \\
2013 & 6,0 & 2,4 & 0,7 & 9,1 \\
\hline
\end{tabular}

Fuente: Construcción propia con base en las cuentas departamentales del DANE.

Por otra parte, el análisis de desempeño fiscal a nivel de grupo-región respalda la relación observada entre el gasto público y PIB, en la medida que la expedición de una serie importante de normas ${ }^{10}$ reorientó el fortalecimiento de las finanzas regionales, desorganizado por muchos años, con el fin de garantizar que el gasto público se ejecute con enfoques de eficiencia productiva y maximización del bienestar colectivo. En este sentido, el análisis de los resultados de la dinámica productiva de los gruposregión vista desde la contribución de la postura fiscal del aparato estatal es consecuente con la hipótesis de como la mejor administración y orientación de

10 Ley 617 de 2000, Ley 358 de 1997, Ley 715 de 2001, acto legislativo 05 de 2011, ley 136 de 1994, Ley 599 de 1999, entre las más representativas. 
los recursos ha originado mayor impacto del gasto público en el crecimiento económico regional.

De los 33 departamentos (incluida Bogotá), se observa como las economías principales en su mayoría fueron las de mejor desempeño fiscal promedio a lo largo de la serie 2000-2013, siendo el Distrito Capital el mejor puntaje $(76,6)$, seguido de Atlántico $(70,0)$ y Cundinamarca $(67,5)$; no obstante, Tolima $(59,5)$ y Valle $(58,8)$, adoptaron una postura fiscal insuficiente que los relegó a los últimos lugares del desempeño fiscal pese su tamaño (Ilustración 6). En las economías principales el mejor desempeño fiscal fue producto de mejoras sustanciales en el respaldo al servicio de la deuda, una progresiva menor dependencia de transferencias y regalías, la optimización de su capacidad de ahorro y principalmente por una mayor generación de recursos propios inducida por el tamaño de sus economías y la mayor diversificación productiva que les es propia cuyos gobiernos aprovecharon fiscalmente.

Ilustración 5. Coeficiente de localización del aporte del valor agregado del gobierno departamental a su PIB (2013)

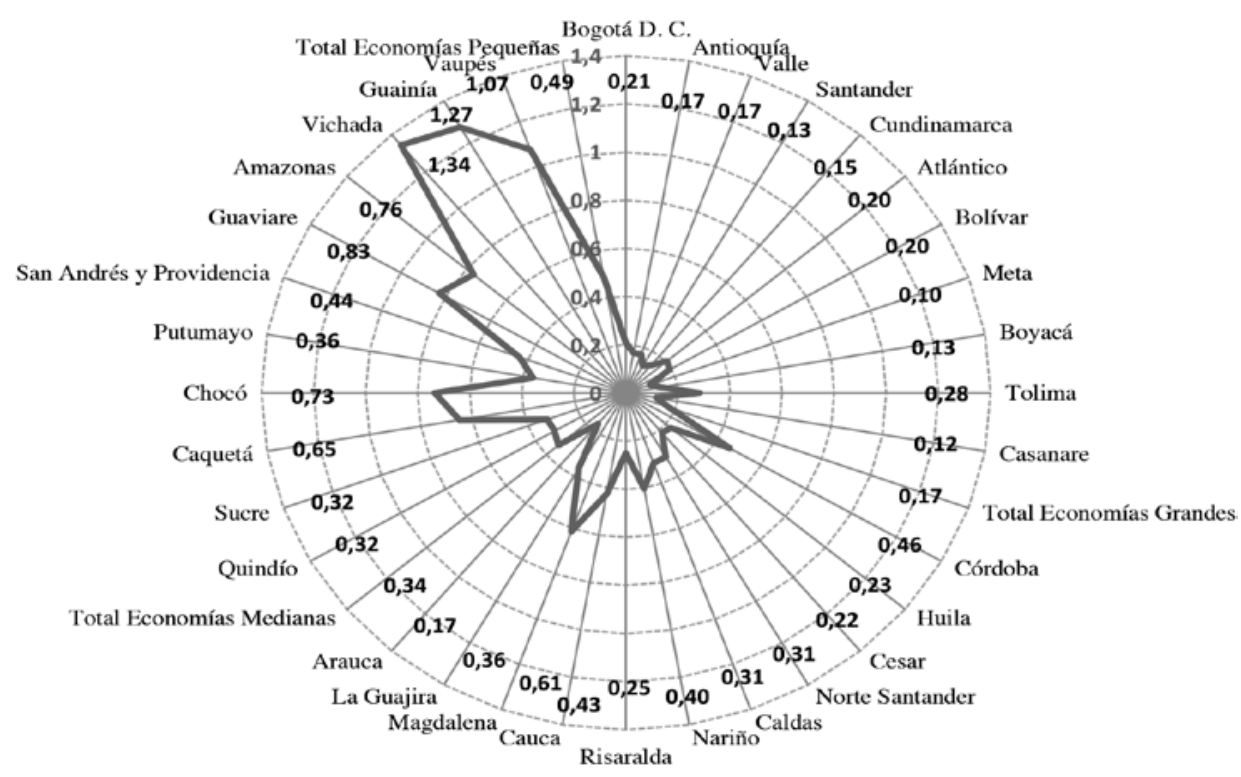

Fuente: Elaboración propia con base en las cuentas departamentales del DANE.

Ilustración 6. Principales Resultados de Desempeño Fiscal - IDF (2000-2013)

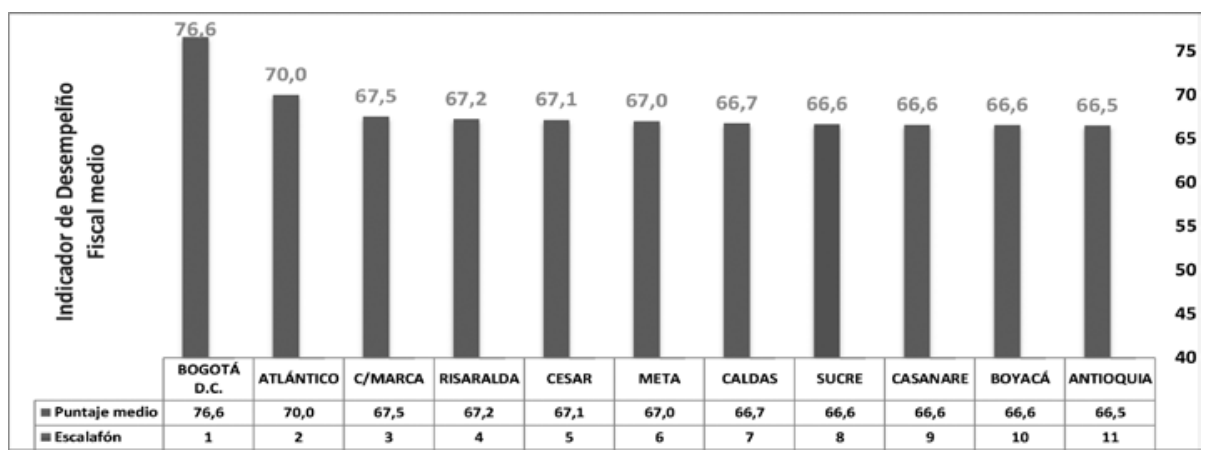

Fuente: Elaboración propia, con base en cifras de IDF del DNP. 
Entre los destacados resaltó el comportamiento de Sucre $(66,6)$, que siendo uno de los departamentos de menor tamaño, equiparó la gestión de economías grandes como Boyacá $(66,6)$ y Antioquia $(66,5)$. Este comportamiento se vio reflejado en la evolución e impacto de su gasto público, particularmente de la formación bruta de capital fijo (187.662 millones de pesos) que representó el 30,3\% del gasto, triplicando su peso en 2012 (10,1\%) sin afectar el déficit fiscal que como proporción del PIB fue ligeramente superior al histórico de la serie (1,1\%). Dicha dinámica impactó positivamente el PIB de este departamento en 2013, tal como lo constatan los indicadores de localización del gasto público, formación bruta de capital fijo y valor agregado departamental (Ilustración 7).

Sin embargo, la mayor parte de las economías intermedias presentó un desempeño fiscal regular y en el caso de las pequeñas economías sucedió lo propio, en cuanto a que su postura fiscal fue insuficiente para intensificar aún más su actividad económica.
De ello se infiere que el tamaño de las economías departamentales resulta relevante para que su comportamiento fiscal tenga mayor incidencia en la actividad, particularmente en la generación de recursos propios, indicador fundamental que lidera las economías principales y en el que las pequeñas tienen una de sus principales restricciones, dada la limitada dimensión y diversidad productiva ya referida.

En este mismo escenario también se aprecia que respecto al tamaño de su economía, algunos miembros representativos de cada grupo-región fortalecieron $y / o$ deterioraron su postura fiscal, sin que esto tuviera influencia directa en el comportamiento de su PIB; por ello, se manifestó una correlación baja entre el PIB regional y su indiciador de desempeño fiscal, lo que conduce a afirmar que en este sentido la disciplina fiscal no constituiría un factor determinante en el crecimiento regional, en razón a una marcada heterogeneidad de comportamientos fiscales disímiles respecto a la dimensión y dinámica de las economías.

Ilustración 7. Indicador de Desempeño Fiscal medio y PIB departamental 2013

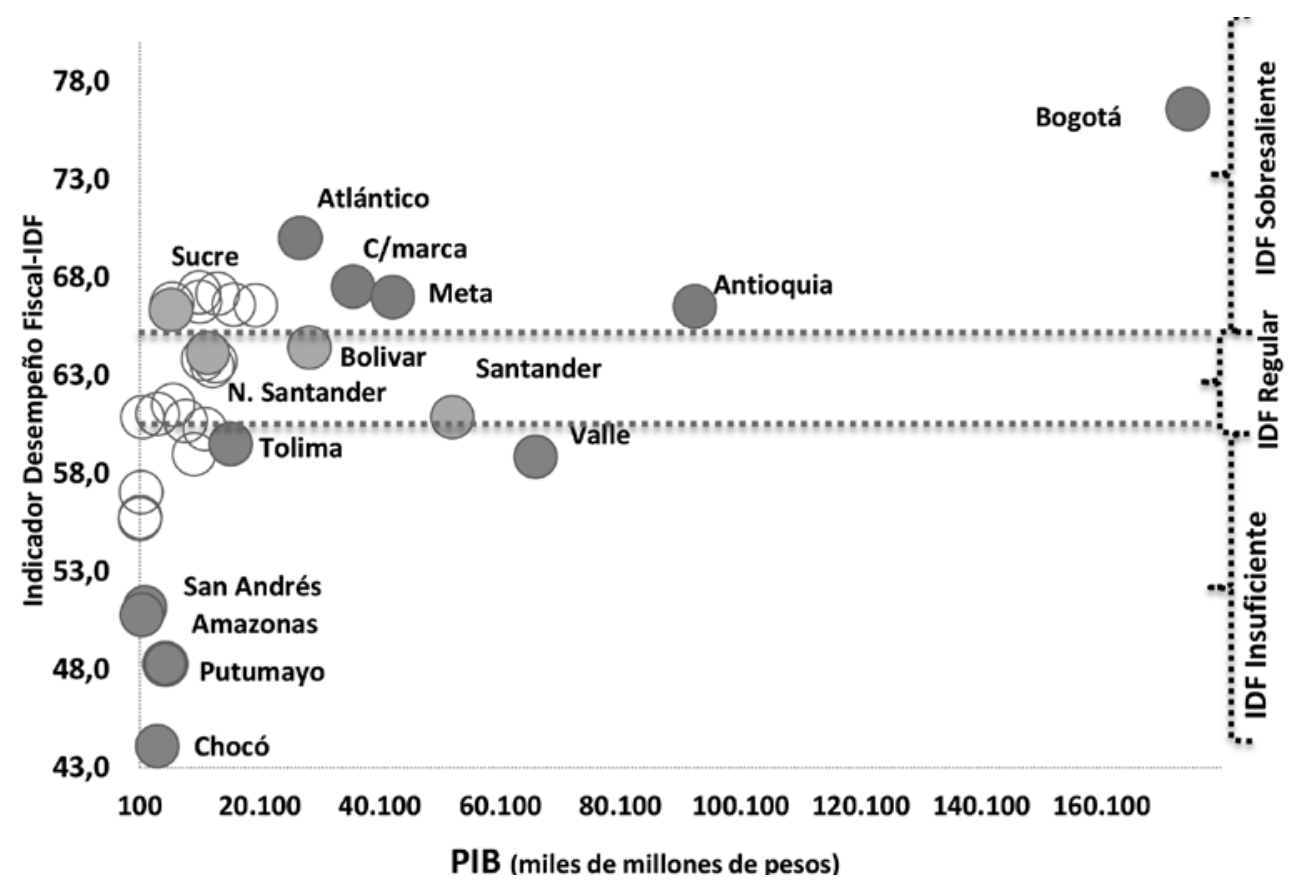

Fuente: Elaboración propia, con base en cifras de IDF del DNP y Cuentas Nacionales del DANE. 


\section{Discusión y consideraciones finales}

La construcción de los resultados presentados fue producto de una juiciosa revisión de las estadísticas regionales de gasto y desempeño fiscal contrastadas a su vez con las cifras de actividad económica, mediante la adopción de distintos enfoques de impacto complementarios entre sí y orientados a identificar a través de diferentes modalidades de provisión el impacto que ha tenido en el PIB departamental el gasto público durante el periodo 2000-2013. Previamente, Mendoza \& Yanes (2014) concluyeron que existe una influencia importante de la acción fiscal del Estado sobre la actividad de las regiones. Este documento aporta nueva evidencia de esta relación, encontrando que por ejemplo en las economías más pequeñas el gasto es un dinamizador natural de su actividad económica haciendo que se especialicen en la provisión de los servicios públicos mucho más que las demás regiones; no obstante, son las economías grandes las que mejor aprovechan sus efectos, potencializados, tanto por su tamaño, como por la diversificación productiva que les es propia.

Las economías principales concentraron el 79,9\% de los puntos porcentuales de aumento del PIB, en tanto las pequeñas sólo aportaron el 3,2\% de ellos. Dichos resultados contrastados con la postura fiscal correspondiente bajo MCO, mostraron una influencia significativa del gasto total, corriente, de inversión social así como de la formación bruta de capital pública en el producto departamental durante el periodo de estudio. El proceso a seguir posteriormente consistió en identificar en qué forma este comportamiento incidió en la marcada diferencia presentada en la contribución al PIB de cada grupo-región.

La incidencia del gasto público en el PIB revelada por el modelo base, se originó por el estímulo fiscal regional en inversión para infraestructura, en especial durante 2013, cuyas contribuciones al crecimiento ofrecen información importante sobre la magnitud del aporte desde diferentes enfoques; en efecto, el análisis de resultados a partir de la medición del impacto efectivo del gasto público en los departamentos evidencia que en las economías principales, el gasto público representa un factor estratégico para potencializar la dinámica del resto de actividades económicas, en tanto que para las economías más chicas, si bien, constituye la fuente primaria de crecimiento en sus regiones, no incide de manera significativa en la evolución y composición del PIB nacional. Este hecho es afín con la tesis de Fuentes (2003), en cuanto a que los efectos del gasto público en infraestructura, no sólo están asociados a su composición sino a las características de las regiones que reciben estos recursos.

Internalizando estos resultados, cabe destacar el salto que se propició en la dinámica del gasto público regional entre 2006-2007, que a nivel total presentó una asignación equivalente entre los gruposregión, ligeramente superior a la media nacional en las economías intermedias y pequeñas. Sin embargo, desde entonces se otorgan mayores cupos a la formación bruta de capital fijo que a las otras categorías de gasto, privilegiándolo sobre los indicadores de ejecución en funcionamiento, tal como lo sugiere Pinilla, et al. (2013) refiriendo los efectos detectados por Tanzi \& Zee (1997), en el sentido que resulta mejor para el crecimiento económico controlar la composición del gasto público antes que su nivel.

Los efectos de este enfoque representaron un mayor impulso en las economías intermedias, que en los demás grupos-región, aunque su efecto ha sido tímido en el fortalecimiento de las capacidades productivas regionales, de tal suerte, que la orientación eficiente del gasto repercutió mejor en las pequeñas economías las cuales presentaron mayor crecimiento, en parte, por disponer de una estructura productiva no diversificada y dependiente del gasto público para crecer, más que por su propio efecto marginal.

Los hechos estilizados muestran como señala Márquez (2012) en alusión a Caminal (2004), que resultaría más eficaz concentrar en mayor medida el gasto público en las economías principales que en las de menor tamaño, gracias a sus efectos encadenados sobre la actividad general, la propia y a los que se producen por su influencia indirecta 'spillovers' en las regiones aledañas. En Colombia, el mejor aprovechamiento de la inversión y gasto públicos que hacen las economías más grandes tiende como lo señalan Mendoza \& Yanés (2014) a aumentar la brecha entre las regiones, aunque por los 
resultados controvertibles que se derivarían de esta línea de política, se enfrentaría el dílema de decidir entre medidas de convergencia regional centralizada a determinados polos de desarrollo o diversificación productiva con desarrollo equitativo.

Por su parte, la localización geográfica de la formación bruta de capital fijo, fue superior en las economías principales como resultado de la ejecución promedio de recursos ligeramente mayor a la media nacional, aunque ampliamente distante respecto a las de las regiones intermedias y pequeñas, que resultaron muy por debajo del promedio del país.

Con los métodos adoptados por caminos diferentes se ha detectado que las regiones más grandes obtienen mejores aportes al crecimiento del PIB derivados del gasto de inversión y los servicios de administración del Estado a pesar que para las economías de menor tamaño estas sean su fuente base de crecimiento. Así mismo, se advierte como los departamentos con mejor localización geográfica en formación bruta de capital fijo, es decir, más especializados que el promedio nacional, han venido enfocando la inversión pública en obras de infraestructura que favorecen la explotación de sus ventajas competitivas en actividades minero-energéticas y no los canalizan hacia una diversificación productiva que permita reducir la brecha respecto al aporte que por ello obtienen las economías principales.

Por otra parte, la comparación de los resultados del PIB regional y su indicador de desempeño fiscal-IDF evidencia que típicamente la mayor parte de las economías grandes son las de mejor comportamiento en la ejecución, aun cuando este sea determinado por sus capacidades para generar ingresos propios, dado el tamaño y estructura de sus economías. Esta mayor autonomía fiscal, contrasta con la dependencia de transferencias y regalías en las pequeñas, las cuales permanecen supeditadas a los giros provistos desde el gobierno nacional central para atender compromisos condicionados de gasto, sobre los cuales no existe mayor margen fiscal discrecional.

Finalmente, se ha confirmado que el desempeño fiscal de los departamentos no influye de manera significativa en el PIB de las regiones ni es referente di- recto para evaluar la hipótesis de que el crecimiento regional antes que estar influenciado por el nivel del gasto público ha estado marcado por la eficacia en la ejecución de las entidades territoriales para honrar los compromisos adquiridos. Fueron detectadas en cada grupo-región posturas fiscales individuales heterogéneas que en algunos casos contrastan con la dimensión y dinámica de sus economías.

De lo anterior se aprecia que si bien, cada conjunto de departamentos predomina en su nicho, se presentan casos en los que el gasto público de economías pequeñas como Sucre es productivo y catapulta el crecimiento de su PIB alternando con las regiones principales, en el sentido que señala Hernández (2009) comentando los trabajos de Barro (1990) y Aschauer (1989), en tanto que otros departamentos como Tolima y Valle a pesar de situarse en los últimos lugares de desempeño fiscal entre las economías pequeñas, su PIB crece por encima del promedio de las principales; lo anterior sumado a que entre el PIB y el IDF existe baja correlación, permite afirmar que la disciplina fiscal en sí misma no determina el crecimiento regional pero la orientación del gasto si refleja que directa e indirectamente produce efectos positivos en la actividad por las externalidades que genera entre la inversión pública y privada. Por tanto, en línea con los argumentos de Hernández (2009), se aprecia como la composición del gasto público y la forma en que se asigna son más efectivos al momento de analizar el impacto que tienen en el fortalecimiento de las capacidades productivas regionales.

\section{Referencias}

Cedillo, E. (2007). La política fiscal desde una perspectiva de crecimiento endógeno, equilibrio presupuestal y fluctuaciones de corto plazo. Recuperado en agosto 19 de 2014. Disponible en línea en http://www.ejournal.unam.mx/pde152/ PDE003915206.pdf

Departamento Administrativo Nacional de Estadística (DANE) (2010). Dirección de Síntesis y Cuentas Nacionales. Cuentas Departamentales - Base 2005: resultados y cambios metodológicos.Recuperado de http://www.dane.gov.co/ files/investigaciones/pib/departamentales/B_2005/Resultados_cambios_metodologicos.pdf. Página 5 .

Departamento Administrativo Nacional de Estadística (DANE) (2013). Cuentas Nacionales Departamentales. [disponible en línea] Recuperado de: http://www.dane.gov.co/index.php/ cuentas-economicas/cuentas-departamentales 
Departamento Nacional de Planeación. (2014). Desempeño Fiscal de los Departamentos y Municipios a 2013. Recuperado en octubre de 2014. Disponible en línea en el vínculo de internet: https://www.dnp.gov.co/programas/desarrollo-territorial/ evaluacion-y-seguimiento-de-la-descentralizacion/Paginas/ desempeno-fiscal.aspx

Díaz, D. \& Revuelta, J. (2009). Gasto Público y Crecimiento en América Latina y España, 1960-2000. Recuperado de http:// www.ugr.es/ montero/XVleep/62.pdf

Fuentes, N. A. (2003). Crecimiento economico y desigualdades regionales en Mexico: el impacto de la Infraestructura. REGION Y SOCIEDAD VOL.XV, No 27. 81-106. Recuperado de: https://www.colson.edu.mx:4433/Revista/Articulos/27/ fuentes.pdf

Galvis, L. \& Roca A. (2000). El crecimiento económico de las ciudades colombianas y sus determinantes. 1973-1998. Recuperado de: http://www.banrep.gov.co/es/dtser-18

Gómez, W. \& Posada, C. (2003). Crecimiento económico y gasto público: un modelo para el caso Colombiano. Bogotá: Subgerencia de estudios económicos, Banco de la República. Recuperado de: http://www.banrep.gov.co/docum/ftp/ borra218.pdf

Hernández, J. (2009). La composición del gasto público y el crecimiento económico. Análisis Económico. Núm. 55, vol. XXIV. Primer cuatrimestre de 2009. Recuperado de http:// www.analisiseconomico.com.mx/pdf/5505.pdf

Márquez, M. (2012). Crecimiento regional y capital público: cuantificación del impacto sobre las regiones españolas de shocks negativos en la inversión pública. Bilbao, España: Recuperado de: http://www.aecr.org/web/congresos/2012/ Bilbao2012/htdocs/pdf/p526.pdf

Mendoza, H. \& Yanes, C. (2014). Impacto del gasto público en la dinámica económica regional. En Revista Finanzas y
Política Económica. Edición Especial: Economía Regional. ISSN: 2248-6046, Vol. 6, No. 1. Enero-junio 2014.Pp. 23-41. Naciones Unidas (1993). Sistema de Cuentas Nacionales 1993. Impreso por la sección de reproducciones de Naciones Unidas. (2008), Sistem of National Accounts 2008 - Preedited version of Volume 1. [Disponible en línea] Recuperado de http://unstats.un.org/unsd.

Necib, H. \& Zakane, A. (2009). Dépenses Publiques et Croissance Économique L'expérience Algérienne. Recuperado en agosto de 2014. 13 pag. Disponible en línea en el vínculo URL: http://www4.fsa.ulaval.ca/files/content/sites/fsa/ files/sections/La_recherche/chaires_recherche/Stephen-A.JARISLOWSKY/ActesHEI/papers/D\%C3\%A9penses\%20 publiques $\% 20$ et $\% 20$ croissance $\% 20 \%$ C3\%A9conomique, $\% 20$ l'exp\%C3\%A9rience\%20alg\%C3\%A9rienne,\%20N.\%20 Hafisa\%20et\%20Z.\%20Ahmed.pdf.

Perilla, J. (2012). La composición sectorial de la inversión en Colombia. Revista de Economia del Rosario. Universidad del Rosario. Vol XV No. 1. Ene-Jun 2012. Pag. 59-122. Recuperado de http://www.urosario.edu.co/urosario_files/75/758d0198-305c-464b-8d4d-388b1f6ce20e.pdf

Pinilla, D. Jiménez, J. \& Montero R. (2013).Gasto Público y Crecimiento Económico. Un estudio empírico para América Latina. En Cuadernos de Economía. Vol. 32 No.59. Bogotá Ene-Jun de 2013. Recuperado en julio de 2014. Disponible en línea en la siguiente URL: http://www.scielo.org.co/scielo. php?pid=S0121-47722013000100009\&script=sci_arttext

Sánchez, R. O. (2006). Crecimiento económico departamental y migración en Colombia. En Archivos de Economía. Bogotá. Documento 317. 1 septiembre de 2006. Departamento Nacional de Planeación, Dirección de Estudios Económicos. Recuperado de https://colaboracion.dnp.gov.co/CDT/Estudios\%20Econmicos/317.pdf 